\title{
Toward the personalization of learning games according to learning styles
}

\author{
Mohamed Ali Khenissi, Fathi Essalmi, Mohamed Jemni \\ Research Laboratory of Technologies of Information and Communication \& Electrical Engineering (LaTICE), Higher School \\ of Sciences and Technologies of Tunis (ESSTT), 5, Avenue Taha Hussein, B.P. 56, Bab Menara, 1008, University of TUNIS, \\ Tunisia \\ khenissi_mouhammed@yahoo.fr, fathi.essalmi@isg.rnu.tn,mohamed.jemni@fst.rnu.tn
}

\begin{abstract}
This paper aims to answer the following question: is it possible to personalize learning games according to learning styles? On one hand, there are several learning styles which could be used to personalize learning. For example, it is possible to personalize learning according to the learning styles active and reflective. On the second hand, learning games differ according to their genres. In fact, there are several games genres such as action and puzzle games. This paper presents two learning games having two different genres. In addition, this paper proposes, argues for and experiments relations which could serve for the personalization of games according to different learning styles.
\end{abstract}

Keywords-component: learning game, genres of games, learning styles;

\section{INTRODUCTION}

In general, the personalization of learning considers the learners' differences. In fact, learners have different characteristics such as their learning styles and media preferences. The personalization allows learners to have the same opportunity for learning given that each learner could study in the appropriate way $[1,2]$.

Furthermore, the use of learning games enhances the motivation of learners. In fact, learning games stimulate the challenge of learners. For that reason, learning games could be an effective approach for learning.

In this context, this paper federates the personalization and the learning games. The objective of this federation is to have both the advantage of the personalization and that of learning games. In order to do that, this paper answers to the following research question: is it possible to personalize learning games according to learning styles?

The answer to this question could be reached by finding relations between genres of learning games and learning styles. For example, it is possible to consider that learning games based on actions are appropriate for learners who have an active learning style. In fact, action games assume that the player is involved at all times in an active way. Consequently, two learning games having two different genres are developed to experiment the proposed relations, the games are used by 70 students in the context of learning the programming language maple. Furthermore, the students' preferences of games and their learning styles are compared. As a result, the feasibility of personalizing learning games according to learning styles is confirmed.

The paper is structured as follows: Section II contextualizes the contribution by analyzing related works. Section III proposes some relations between genres of games and learning styles. Section IV presents the implementation of two learning games. Section $\mathrm{V}$ describes the experimentation and discusses the results. Finally, section VI concludes the paper with a summary of the work and future research directions.

\section{RELATED WORKS}

Researchers have demonstrated the effectiveness of learning games in many domains such as learning of geography, human language, safety and so on. For example, VR-ENGAGE [3] is used for teaching geography. In VRENGAGE, The ultimate goal of a player is to navigate through a virtual world and find the missing pages of the book of wisdom, which is hidden. To achieve the ultimate goal, the player has to be able to go through all the passages of the virtual world that are guarded by dragons and obtain a score of points, which is higher than a predefined threshold. The total score is the sum of the points. Concerning human language teaching, Games Factory is considered. Games Factory is a games-authoring system which allows to generate games for teaching spatial relations in text narratives. In games generated by Games Factory, the player is tasked with retrieving objects from rooms in a particular order and in a limited amount of time, receiving points based on their performance. Wii [5] is used for teaching IR (a phenomenon of electromagnetic radiation. IR is also a technology supporting Wii). In Wii, participants physically wave the Wii remote to virtually embody the simulated player or avatar in the digital game. Wii is used to study the transition of students' interest from the initial interest motivated by the game (Wii) to the technology supporting that game (IR). Triage trainer demonstrator [6] is used for training the practice of sorting through casualties in order of priority. The Triage trainer demonstrator uses a first person shooter style of the game with high levels of fidelity. In this way, the learner experiences the scene of the explosion, then 
they explore the scene by moving around it, encountering the casualties and undertaking the correct procedures of testing for vital signs, then sorting the casualties. Once completed the trainee undertakes an after action review, where the trainees scores present the order of testing for vital signs, tagging and the time of sorting are listed against the ideal settings. Secure game [7] is used for task solving in the area of work safety. Secure game includes different types of puzzles; some can be solved individually, but others require effort and commitment from the whole team for successful completion. The different levels of script follow the progression in the game, where higher levels can be reached by solving problems set for the players. Idea Storming Cube [8] is used for presenting new ideas about a problem-solving task. In Idea Storming Cube, a learner is considered as winner when he/she generates the largest amount of valid new ideas in a given period of time. The user can get the privilege of rotating the cube and seeing ideas from other peers to stimulate more ideas. Learning versions of Tetris [9] are used for teaching precedence relationship between activities. The classical game of Tetris consists of a sequence of geometric figures falling down at various rates. The learning version of Tetris was created by mapping the geometric constraints to the precedence relationships between activities [10]. A player who is able to match these precedence constraints achieves a high-score or a high semantic fit. Classroom Multiplayer Presential Role Playing Game (CMPRPG) is used for teaching notions of dynamic ecosystem equilibria [11]. Notions of dynamic ecosystem equilibria are applied to given situations: prey and predator. Notions of rupture of the ecosystem equilibria by natural factors are applied to given situations. In each situation, players have to collaborate in groups to find a solution for the situation. Table I presents examples of learning games classified according to their pedagogical objective.

TABLE I. EXAMPLES OF NUMERIC LEARNING GAMES CLASSIFIED ACCORDING TO THE PEDAGOGICAL OBJECTIVE

\begin{tabular}{|l|l|}
\hline \multicolumn{1}{|c|}{ Learning game } & \multicolumn{1}{|c|}{ Pedagogical objective } \\
\hline VR-ENGAGE [3] & Teaching geography \\
\hline $\begin{array}{l}\text { Games generated by } \\
\text { Games Factory which } \\
\text { is a games-authoring } \\
\text { system [4] }\end{array}$ & $\begin{array}{l}\text { Preparing readers to comprehend and } \\
\text { retain spatial relations in text narratives. }\end{array}$ \\
\hline Wii [5] & $\begin{array}{l}\text { Teaching IR (a phenomenon of } \\
\text { electromagnetic radiation. IR is also a } \\
\text { technology supporting Wii) }\end{array}$ \\
\hline $\begin{array}{l}\text { Triage trainer } \\
\text { demonstrator [6] }\end{array}$ & $\begin{array}{l}\text { Training the practice of sorting through } \\
\text { casualties in order of priority }\end{array}$ \\
\hline $\begin{array}{l}\text { Secure game [7] } \\
\text { Idea Storming Cube }\end{array}$ & $\begin{array}{l}\text { Presenting new ideas about a problem- } \\
\text { solving task. }\end{array}$ \\
\hline $\begin{array}{l}\text { A learning version of } \\
\text { Tetris [9] }\end{array}$ & $\begin{array}{l}\text { Determining the precedence relationship } \\
\text { between activities }\end{array}$ \\
\hline $\begin{array}{l}\text { CMPRPG: Classroom } \\
\text { Multiplayer Presential } \\
\text { Role Playing Game } \\
\text { [11] }\end{array}$ & $\begin{array}{l}\text { Teaching notions of dynamic ecosystem } \\
\text { equilibria (from the ecology domain) }\end{array}$ \\
\hline
\end{tabular}

Table I shows that there are two alternatives to develop learning games. The first one is the development of new game such as the development of VR-ENGAGE [3]. The second alternative consists of adapting an existing (already developed, but not used for education) game to be used for education such as the development of a learning version of Tetris [9]. Furthermore, the table shows that learning games have different genres. For example, the genre of the learning version of Tetris [9] could be seen as puzzle. The differences of learning games genres could be linked to the individual differences of learners. In fact, it is possible to personalize learning games based on the association of learning styles with genres of learning games.

Learning styles are commonly used for personalizing learning. For example, the personalization system AHA! [12] considers the Felder-Silverman learning styles for personalizing learning. However, learning styles are not used for personalizing learning games. This work aims to study the feasibility of personalizing learning games according to the learning styles. This will allow to benefit from the richness of learning styles when personalizing learning games.

\section{RELATION BETWEEN LEARNING GAMES AND LEARNING STYLES}

This section presents the proposed relations between the genres of learning games and the learning styles of the Felder-Silverman learning styles model. Before presenting the proposed relations, we present a description of the learning styles and genres of games.

Concerning learning styles, they are presented by linguistic variables [13]. For example, the set of values used in the literature for the model of Felder-Silverman learning styles is active/reflective; sensing/intuitive; visual/verbal; sequential/global \} [14]. Active learners like to try things out or do something active while reflective learners prefer thinking about things on their own. Sensory learners like learning facts and solving problems with known methods while intuitive learners prefer discovering possibilities. Learners who have visual learning style like pictures, diagrams, flow charts while learners who have verbal learning style like written and spoken explanations. Learners who have sequential learning style learn better step by step while learners who have global learning style understand things as a whole. These learning styles could be determined automatically by using the 44-item questionnaire available online [15].

Concerning the games genres, the following genres are used in our proposed relations [16].

- Action. Keeps the player moving and involved at all times. Primary skills are eye/hand coordination and quick reflexes. Deep thinking is generally not required.

- Puzzle Games. Puzzles are presented on their own without story or content action. Puzzle Games 
assume that players benefit from each achieved step in order to do the current step.

This study assumes that there are some relations between learning styles and genres of games. As an example of assumed relation, we cite the relation between the learning style active and the learning games based on actions. In fact, action games assume that the player is involved at all times in an active way. As another example we consider that sequential learning style is related to games based on puzzle. In fact, learners who have sequential learning style prefer learning step by step. Furthermore, puzzle learning games assume that learners benefit from each achieved step in order to do the current step.

Table II presents the proposed relations between the learning styles of the Felder-Silverman learning styles model and the genres of learning games.

TABLE II. EXAMPLES OF RELATIONS BETWEEN LEARNING STYLES AND GENRES OF GAMES

\begin{tabular}{|c|c|}
\hline Learning style & Genres of games \\
\hline $\begin{array}{l}\text { Active (of Active/Reflective } \\
\text { dimension of Felder-Silverman } \\
\text { learning styles model) }\end{array}$ & Games based on action \\
\hline $\begin{array}{l}\text { Sequential (of Sequential/Global } \\
\text { dimension of Felder-Silverman } \\
\text { learning styles model) }\end{array}$ & Games based on puzzle \\
\hline
\end{tabular}

\section{IMPLEMENTATION}

Two learning games have been implemented. The first one is called Instruction Right Place Game (IRPG) and it allows learners to benefit from the drag and drop technology to construct a program (from the programming language maple) in an amusing way. IRPG is considered as puzzle game. In fact, it allows learners to construct a program step by step. Furthermore, the learners receive feedback on the realized instructions and benefit from the feedback to do the next instruction. The second game is a Learning version of Pacman Game (LPG) and motivates learners to correctly answer the questions of the programming language Maple. LPG is considered as an action game. In fact, it keeps the learners moving and involved in order to conduct Pacman correctly.

Figure 1 presents the interface of the first game (IRPG). This interface contains three containers and two avatars. Concerning the containers, the left one includes the question to be solved by the players. The middle container includes elements from the answer to the questions (set of unordered instructions). The right container includes a set of subcontainers in which the learner should move instructions (from the middle container) in the correct order to form a program. Concerning the avatars, one (on top of the question) represents the face of a devil that challenges the learner to answer questions. It reacts negatively (angry) if the learner answers correctly, and it is happy when the learner' response is wrong. The other avatar is the face of an angel who tries to help the learner by guiding him/her to the correct answer, it seems angry when the learner makes a mistake and happy when the response is correct. These avatars make the learning game very funny. Above the angel, we find a section used to display messages to help the learner.

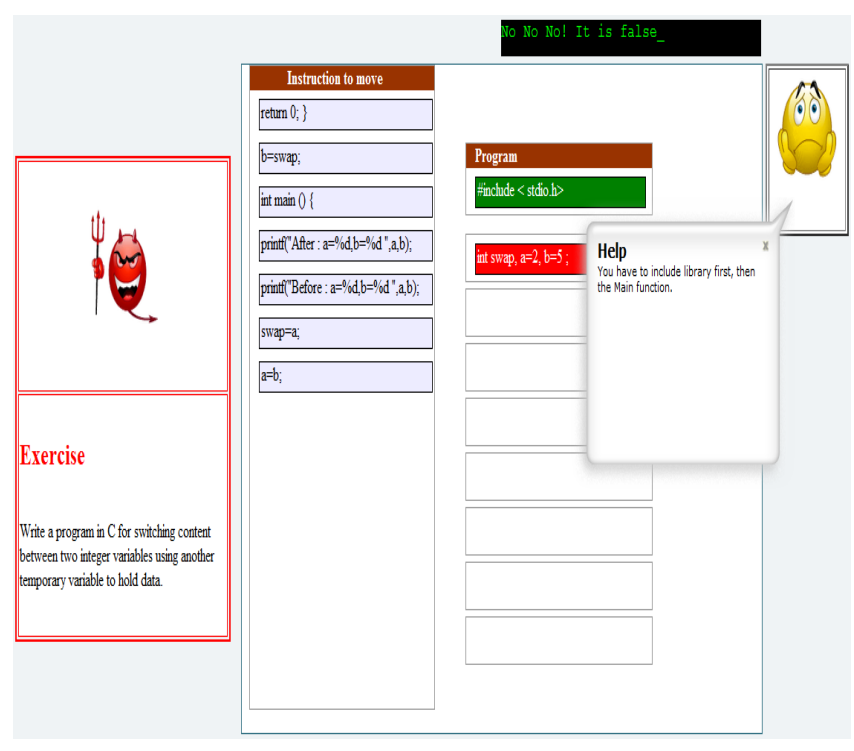

Figure 1. Instruction Right Place Game

The IRPG was implemented by using HTML, JavaScript, CSS and Ajax with the integration of free components and avatars.

The learner begins the game by reading the statement of the exercise, then reads the instructions of the program which are sorted in unordered way. Next, the learner tries to find a precedence relation between these instructions and find, for example, the first instruction and move it with the mouse into the first container. After that, the learner puts another instruction into another sub-container, until building the program.

If the learner moves an instruction to non-appropriate sub-container, the color of the sub-container will be red, the devil avatar will be happy while the angel avatar will be angry and a help message is displayed.. In this case, the learner may return the instruction in the middle container and move another instruction which could be appropriate.

If the learner moves the instruction to appropriate subcontainer, the color of the sub-container will be green, the angel avatar will be happy, the devil avatar will be angry, and a message is displayed informing that the answer is right. Once the learner has completed the construction of the program, a question (for evaluation) will be displayed, in order to test the learner's understanding of the program. After the response, a note / 20 will be displayed, taking into account the mistakes that the learner makes in the program.

To facilitate the construction of the IRPG games, a teacher interface has been implemented in which the teacher can write the questions, which will appear in the learner 
interface. In addition, the teacher edits the instruction in the correct order, and the evaluation question. Finally, the teacher clicks on the save button for the creation of a new game.

Figure 2 presents the interface of the second game (LPG). In the traditional version of Pacman Game, the player maneuvers Pacman in a maze, while Pacman eats the stars in the maze. There are also four ghosts in the maze who try to catch Pac-Man, and if they succeed, Pacman loses a life. There are four power-up items in the corners of the maze, called power stars. After Pacman eats a power star, the ghosts turn blue for a short period; they slow down and try to escape from Pacman. During this time, Pacman is able to eat them [17].

Concerning the LPG, when Pacman eats a power star, the learner has to respond to a question (about the programming language maple) in order to continue the game having a 'reverse' role (Pacman can move freely and eat the enemy for a short period).

Before continuing the game, the learner's score of his/her answer to the question will be displayed. Furthermore, the incorrect responses and the correct answer will be displayed. If the learner's score is greater than the average, Pacman can move freely and eat the enemy for a short time, otherwise the learner will not get this bonus.

When the learner finishes the game, a score $/ 20$ is displayed. Else when he/she failed to finish the game, the attempts has expired, a score / 20 is calculated and displayed with an invitation to play again.

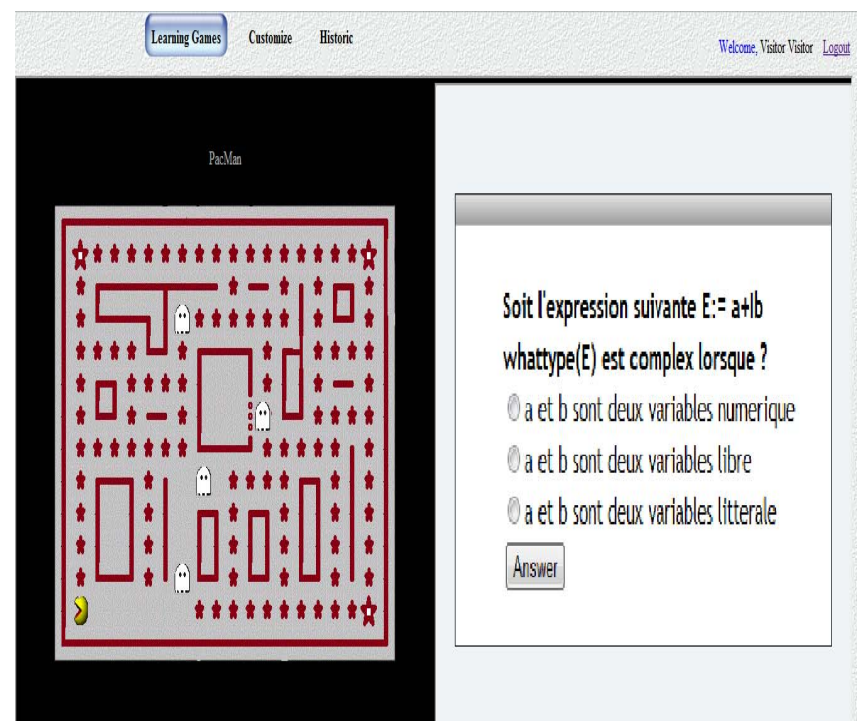

Figure 2. A Learning version of Pacman Game.

To facilitate the construction of these games, a teacher interface has been implemented in which the teacher can create questions and click on the save button for the generation of a new learning game.

\section{EXPERIMENTATION}

In this section, we will describe, first, an experimentation about the validity of the learning games. In fact we have to demonstrate the validity of our learning games before proceeding to the next step which is the checking of the relationship between learning styles and genres of games. So, in order to validate in an empirical way the effectiveness of our learning games, the first subsection describes a classroom and an online experimentation.

Then, the second subsection describes experimentation about the relation between learning styles and genres of games. In fact, students' preferences of learning games and their learning styles are analyzed in order to check the relations proposed between them. In particular, the relation between the learning style active and the learner's preference of an action game is confirmed. However, the relation between the learning style sequential and the learner preference of a puzzle game is partially confirmed.

\section{A. Experimentation about the validity of the learning games}

\section{1) Classroom Experimentation}

The first experiment involved 60 students of the first grade of a tertiary school in Tunisia (ISSAT Gabes), during November 2011. Students are affected arbitrary to two subgroups. The first group includes 30 students that will use the learning games to learn the programming language Maple. The second group includes 30 students that will learn the same course in traditional way. The students of the first group will use personal computers available in the computers rooms of the ISSAT Gabes for connecting to the web server delivering the games.

After the success of the first experiment, we have increased the number of participants in the same tertiary school during January 2012, and so, the number of the students (in the classroom experimentation) who have used our system was 70 .

Before using learning games, the students of both groups, were requested to work on a pre-test using paper and pencil. This pre-test was an ordinary classroom test in which every student had to answer questions by filling in a test paper. The student's note in the pre-test was compared to the student's notes in a post-test that was given to the students after the use of the learning games and the traditional learning respectively. The comparison of students' results in the pretest and the post-test was used to draw conclusions about the learning games effectiveness compared to the simple traditional learning.

After having learned through the learning games, traces of students are analyzed and interpreted. In addition the averages of students' scores in the pre-test and the post-test are calculated. These averages show that, in average, students of the experimental and control groups have similar levels of knowledge before starting the experimentation (13.62 for the experimental group and 13.35 for the control group). However, after the experimentation, the level of the students in the experimental group is greater than the level of 
the students in the control group (15.48 for the experimental group and 14.57 for the control group). This result shows that using the learning games has positive impact on learning. Table III presents the average of learners score in pre-test and post-test.

TABLE III. AVERAGES OF LEARNERS SCORE

\begin{tabular}{|l|l|l|}
\hline & Experimental group & Control group \\
\hline Pre-test & 13.62 & 13.35 \\
\hline Post-test & 15.48 & 14.57 \\
\hline
\end{tabular}

The results of this experiment showed that students benefited from learning games which represents an amusing teaching way.

In addition, we have adapted the Technology Acceptance Model (TAM) [18]. TAM is among the most widely used model for the validation of the information systems (IS). It has being extensively applied into many types of IS including business, government, e-commerce, internet banking, e-learning, and other online applications. TAM postulated that usefulness and ease of use are the main factors to predict behavioral intention. Specifically, students of the first group (experimental group) were requested to answer to a questionnaire validated in the literature. An instance of the questionnaire is developed for determining the student satisfaction when using the game for learning. The questionnaire includes instances of the 4 items for Usefulness (U) and the 4 items for Ease Of Use (EOU). The questionnaire includes also instances of the 4 items for attitude toward using the sys-tem (ATT) and the 3 items for behavioral intention to use the system (INT) presented in [19]. Beside each item of the questionnaire, 7 values on Likert scale ranging from 1 for the total agreement to 7 representing the total disagreement.

Averages and medians of the students' responses to the questionnaire are calculated. An average nears 1 expresses that, in average, the students are very satisfied when using the learning games. However, an average nears 7 expresses that, in average, students are very dissatisfied when using the learning games. Furthermore, a median such as 1 expresses that most students are very satisfied. Table IV presents the averages and medians for the variables Usefulness (U), Ease Of Use (EOU), attitude toward using the system (ATT) and behavioral intention to use the system (INT).

TABLE IV. AVERAGES AND MEDIANS OF LEARNERS SATISFACTION

\begin{tabular}{|l|l|l|l|l|}
\hline & \multicolumn{1}{|c|}{ U } & \multicolumn{1}{c|}{ EOU } & \multicolumn{1}{c|}{ ATT } & \multicolumn{1}{c|}{ INT } \\
\hline Average & 2.22 & 1.67 & 2.23 & 2.44 \\
\hline Median & 2 & 1 & 2 & 2 \\
\hline
\end{tabular}

Table IV shows that, in average, students are very satisfied when using the learning games. In fact, the averages for the variables U, EOU, ATT and INT are nears 1 and far from 7. For example, the average of the variable EOU is 1.67. Furthermore, the medians of the variables show that most students are very satisfied when using the games. For example, the median of the variable EOU is 1 .

\section{2) Online Experimentation}

The two learning games were made online at the Webpage http://affectationgame.hebergratuit.com/ for the IRPG game and at the http://learningversionofpacmangame.hebergratuit.com/ for the LPG. In fact, we have hosted the two learning games on a server. Then, we have integrated the plugin "Like" of the social network facebook in our site. In fact, the facebook developer's page offers a web-based configuration tool to help users get the code required to add to their website.

In addition, we have invited people on facebook to play the two learning games. We have obtained more than 600 like for the IRPG and more than 300 for the LPG. After that, we have found a problem. Indeed, we cannot list the facebook users who liked the two learning games. After researching, we found this declaration available in the facebook site "The plugin only displays friends photos. If the user does not have friends who have liked your page or have connected to your site, no faces will be shown". So, to solve this problem we have used Google Analytics, it is a free service offered by Google that generates detailed statistics about the visitors of a Website.

After the installation, we observed some information about the last 500 users who have visited the IRPG and the last 300 users who have visited the LPG. Visitors are distributed on 61 country and they spent in average 2 minutes to play for the IRPG and from 55 country and they spent in average 3 minutes to play for the LPG.

\section{B. Experimentation about the relation between learning styles and genres of games}

Students' preferences of games and learning styles are analyzed in order to check the relations proposed in the table II. To do that, students' preferences of IRPG and LPG are requested from students. Then, the relations between the students' preferences of games and their learning styles are analyzed. In particular, the relation between the learning style active and the learner's preference of an action game (the LPG) is confirmed. However, the relation between the learning style sequential and the learner's preference of a puzzle game (the IRPG) is partially confirmed.

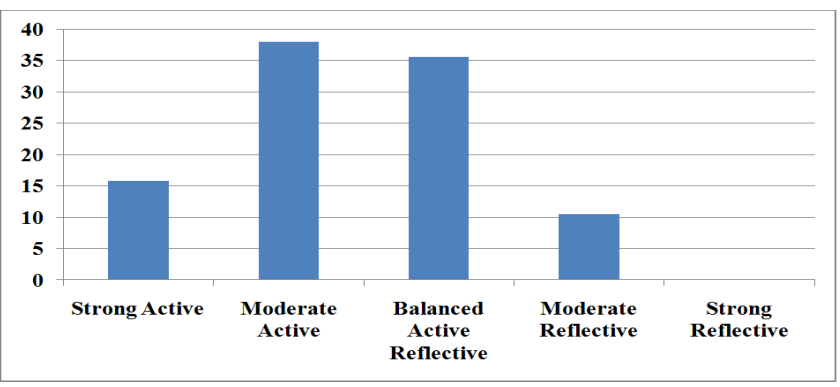

Figure 3. Relation between the learning style active and LPG game

Figure 3 presents the analyses of the relation between the learning style active and the learner preference of the 
learning version of Pacman game. The figure shows that the learning styles of all students who prefer the learning version of Pacman Game are active. This confirms the relation between the learning style active and the learner's preference of action games.

Figure 4 presents the analyses of the relations between the learning style sequential and the learner's preference of the IRPG. The figure shows that the learning styles of most of the students who prefer the IRPG are not far from sequential. This partially confirms the relation between the learning style sequential and the learner's preference of puzzle games.

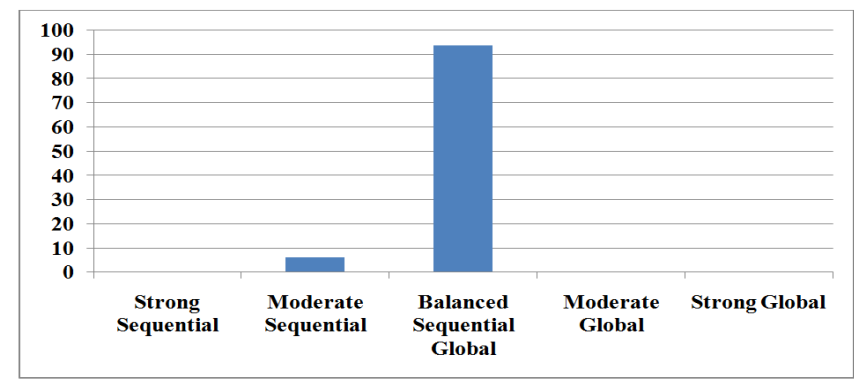

Figure 4. Relation between the learning style sequential and the IRPG game

\section{CONCLUSION}

The paper presents two learning games. The first one is based on the drag and drop technology (IRPG) which is considered as puzzle game. The second game is the LPG which is considered as an action game.

This work checks the relations between genres of games and learning styles. In particular, the work confirms the relation between the learning style active and action game and partially confirms the relation between the learning style sequential and puzzle game. Future works will check additional relations between genres of games and other learning styles. For example, it is possible to consider the relation between the reflective learning style and the learning games based on strategy. In fact, reflective learners prefer thinking about things on their own. Similarly, strategic games assume that learners prefer spending times in reflection. In addition, we will implement a recommendation system that predicts the convenient learning games for a particular student based on students' navigation history [20, 21].

\section{REFERENCES}

[1] H. Chorfi \& M. Jemni, PERSO:"A System to customize e-training, 5 th International Conference on New Educational Environments", May 26-28 2003, Lucerne, Switzerland.

[2] Fathi Essalmi, Leila Jemni Ben Ayed, Mohamed Jemni, "A MultiParameters Personalization Approach of Learning Scenarios", The 7th IEEE International Conference on Advanced Learning Technologies, July 2007, Nigata, Japan.

[3] Virvou, M., Katsionis, G., \& Manos, K. (2005). Combining Software Games with Education: Evaluation of its Educational Effectiveness. Educational Technology \& Society, 8 (2), 54-65.
[4] Smith, G. G., Majchrzak, D., Hayes, S., \& Drobisz, J. (2011). Computer Games versus Maps before Reading Stories: Priming Readers' Spatial Situation Models. Educational Technology \& Society, 14 (1), 158-168.

[5] Ting, Y.-L. (2010). Using Mainstream Game to Teach Technology through an Interest Framework. Educational Technology \& Society, $13(2), 141-152$.

[6] Freitas, S d and Neumann, T.(2009).The use of 'exploratory learning' for supporting immersive learning in virtual environments, Computers \& Education, 52, 343-352.

[7] Hämäläinen, R., Oksanen, K., \& Häkkinen, P. (2008). Designing and analyzing collaboration in a scripted game for vocational education, Computers in Human Behavior, 24, 2496-2506.

[8] Huang, C.-C., Yeh, T.-K., Li, T.-Y., \& Chang, C.-Y. (2010). The Idea Storming Cube: Evaluating the Effects of Using Game and Computer Agent to Support Divergent Thinking. Educational Technology \& Society, 13 (4), 180-191.

[9] Zualkernan, I. A. (2006). A framework and a methodology for developing authentic constructivist e-Learning environments. Educational Technology \& Society, 9 (2), 198-212.

[10] Zualkernan, I. A., \& Parmar, F. (2004). AGORA - An Engine for Automatic Generation of Game-Based Incidental e-Learning Environments from UML Activity Diagrams. Paper presented at the 2004 International Research Conference on Innovation in Information Technology, October 4-6, 2004, Dubai, UAE.

[11] Susaeta, H., Jimenez, F., Nussbaum, M., Gajardo, I., Andreu, J. J., \& Villalta, M. (2010). From MMORPG to a Classroom Multiplayer Presential Role Playing Game. Educational Technology \& Society, 13 (3), 257-269.

[12] Stash, N., Cristea, A., \& de Bra, P. (2006). Adaptation to Learning Styles in ELearning: Approach evaluation. In T. Reeves \& S. Yamashita (Eds.), Proceedings of world conference on e-learning in Corporate, Government, Healthcare, and Higher Education (pp. 284 291). AACE: Chesapeake, VA.

[13] F. Essalmi, L. J. B. Ayed, M. Jemni, Kinshuk, S. Graf. (2010). “A fully personalization strategy of E-learning scenarios", Computers in Human Behavior, Elsevier doi: 10.1016/j.chb.2009.12.010.

[14] Felder, R. M., \& Silverman, L. K. (1988). Learning and teaching styles in engineering education. Engineering Education, 78(7), 674681.

[15] Felder, R. M., Soloman, B. A. Index of learning styles, http://www4.ncsu.edu/unity/lockers/users/f/felder/public/ILSpage.ht $\mathrm{ml}$

[16] Joanne Gikas \& Richard Van Eck. (2004). Ph.D. Integrating Video Games Into the Classroom: Where to Begin? The University of Memphis.

[17] Szita, I., Lorincz, A. (2007). Learning to Play Using LowComplexity Rule-Based Policies: Illustrations through Ms. Pac-Man. Journal of Arti_cial Intelligence Research 30 659-684.

[18] Davis, F.D. (1989). Perceived usefulness, perceived ease of use, and user acceptance of information technology. MIS Quarterly. 13(Sep 1989): p. 319-340.

[19] Masrom, M. (2007). Technology acceptance model and E-learning. In 12th International conference on education. sultan Hassanal Bolkiah Institute of Education, Universiti Brunei Darussal.

[20] M.K. Khribi, M. Jemni, O. Nasraoui, "Toward Integrating the Pedagogical Dimension in Automatic Learner Modeling within ELearning Systems", The 9th IEEE International Conference on Advanced Learning Technologies, July 14-18, 2009 Riga, Latvia.

[21] M.K. Khribi, M. Jemni, O. Nasraoui, "Automatic Recommendations for E-Learning Personalization Based on Web Usage Mining Techniques and Information Retrieval", The 8th IEEE International Conference on Advanced Learning Technologies, July 1st- July 5th, 2008 Santander, Cantabria, Spain. 